\title{
HISTOPATHOLOGICAL SPECTRUM OF MEDIASTINAL LESIONS IN A TERTIARY CARE CENTRE, ANDHRA PRADESH, INDIA
}

\author{
Gayathri Devi Parasa1, Keerthi Reddy Remala², Satya Prakash Venkatachalam Turlapati
}

${ }^{1}$ Associate Professor, Department of Pathology, GSL Medical College, Rajamahendravaram, Andhra Pradesh, India.

${ }^{2}$ Assistant Professor, Department of Pathology, GSL Medical College, Rajamahendravaram, Andhra Pradesh, India.

3 Professor and HOD, Department of Pathology, GSL Medical College, Rajamahendravaram, Andhra Pradesh, India.

\section{ABSTRACT}

\section{BACKGROUND}

Mediastinal lesions are uncommon and infrequent, encountered as mediastinal masses with wide histopathological spectrum which cause diagnostic difficulty to the clinicians and radiologists because of the variations of presenting symptoms, locati on and accessibility. Mediastinal lesions also pose difficulty in obtaining samples directly by Fine Needle Aspiration or Needle Core Biopsy technique, Ultra Sound/ Computed Tomography guided techniques aid in getting adequate material and to arrive at a definitive diagnosis in cases where resection of the lesion is not possible, and accessibility is poor. We wanted to present the spectrum of histopathological diagnosis of various mediastinal lesions both benign and malignant, encountered in this institution, a tertiary care center in India.

\section{METHODS}

This is a retrospective study conducted from June 2015- December 2018 on Fine Needle Aspirations (FNA), Needle Core Biopsies (FNB) and surgically resected specimens of all mediastinal lesions sent to the Department of Pathology for histopathological examination.

\section{RESULTS}

A total of 43 cases of mediastinal lesions was taken into consideration. Out of these 43 cases, 17 (39.53\%) were CT guided FNA, 5 (11.63\%) CT guided FNBs and 21 (48.84\%) were excised specimens. In 3 (6.97\%) of these cases of FNA diagnosis was inconclusive and in $2(4.65 \%)$ cases no opinion could be given as material was necrotic and inadequate. Of the total 43 cases 27 (62.8\%) cases were males and about $16(37.2 \%)$ were female patients. M:F ratio was 1.7:1. Age distribution was between $04-70$ yrs. 4 (9.30\%) of the cases were in paediatric age group (<16 yrs.) and $39(90.60 \%)$ were in adult age group ( $>16$ yrs.). Mean age in adults was (47.7 yrs.).

\section{CONCLUSIONS}

The present study emphasizes on the importance of awareness of various lesions that can occur in mediastinum, spectrum of histopathological variants and a definitive diagnosis in guiding the treating clinician to initiate the appropriate treatment at the earliest especially in cases of malignancies and non resectable lesions. Wherever necessary IHC should be done. In the present study, thymic lesions and lymphomas are the most common lesions encountered in adults (8 and 7 of the total 43 lesions). In paediatric age group, we encountered two thymic cysts and two lymphomas of which one was Hodgkin's and the other was NonHodgkin's lymphoma.

HOW TO CITE THIS ARTICLE: Parasa GD, Remala KR, Turlapati SPV. Histopathological spectrum of mediastinal lesions in a tertiary care centre, Andhra Pradesh, India. J. Evolution Med. Dent. Sci. 2019;8(20):1651-1655, DOI: 10.14260/jemds/2019/365

\section{BACKGROUND}

Mediastinal lesions are uncommon lesions which occur in the central portion of the thoracic cavity, limited by pleural cavities laterally, thoracic inlet superiorly, the diaphragm inferiorly and vertebral column posteriorly. Diagnosis of these lesions is a difficult task for clinicians, radiologists and pathologists because of its variable presentation clinically, inaccessibility and also due to histomorphological variations. Mediastinal masses present as space occupying masses situated in different compartments of mediastinum namely superior, anterior, middle, and posterior compartments and present with wide variety of signs and symptoms.

'Financial or Other Competing Interest': None.

Submission 20-03-2019, Peer Review 01-05-2019,

Acceptance 09-05-2019, Published 20-05-2019.

Corresponding Author:

Remala Keerthi Reddy,

GSL Medical College,

Lakshmi Puram, Rajmahendravaram-533296,

EG District, Andhra Pradesh, India.

E-mail: remala.keerthireddy@gmail.com

DOI: $10.14260 /$ jemds $/ 2019 / 365$

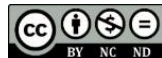

In general, these lesions account for $<1 \%$ of all mediastinal tumours and the thymic tumours account for less than $1 \%$ of all neoplasms in children. These lesions can be neoplastic or non-neoplastic, primary or secondary, and show histopathologically different types and variants. Primary mediastinal tumours are mostly thymic, followed by lymphatic, neurogenic and mesenchymal origins. Most common lesions in adults are thymomas and Non-Hodgkin's lymphomas. Thymus is an important organ housed in the anterior mediastinum and thymoma is the most common tumour of the thymus with an incidence of 0.15 per 100,000 person years. Thymomas and thymic carcinomas are uncommon tumours that occur at almost all ages (Range 0-90 years) with a peak incidence between 40-70 years while occurrence of thymomas is exceedingly rare in children and adolescents. The histological typing of thymic tumours remains a challenge for surgical pathologists. Metastatic carcinomas to hilar and other lymph nodes also present as mediastinal masses and it is essential to diagnose these masses so as to decide the treatment modality to be followed. The other rare lesions that can occur in mediastinum include 


\begin{tabular}{|c|c|c|c|c|}
\hline $\begin{array}{l}\text { Sl. } \\
\text { No. }\end{array}$ & Diagnosis & $\mathbf{n}=$ & $\%$ & $\begin{array}{l}\text { Age in } \\
\text { Years }\end{array}$ \\
\hline \multicolumn{5}{|c|}{ Benign Lesions } \\
\hline 1 & Thymomas- A (1), B1 (3), AB (2), B (2) & 8 & 19.5 & $20-70$ \\
\hline 2 & $\begin{array}{c}\text { Thymic cysts (2), } \\
\text { Thymic lipoma(1), } \\
\text { Thymic hyperplasia(1) }\end{array}$ & 4 & 9.75 & $\begin{array}{l}4 \& 7 \\
41-50 \\
31-40 \\
\end{array}$ \\
\hline 3 & Schwannoma & 1 & 2.43 & 23 \\
\hline 4 & Mature teratoma & 1 & 2.43 & 25 \\
\hline 5 & $\begin{array}{l}\text { Mesenchymal spindle cell tumours (SFT, } \\
\text { IST, BSN)* }\end{array}$ & 3 & 7.31 & 63, \\
\hline 6 & Colloid goiter & 1 & 2.43 & \\
\hline Total & & 18 & 41.8 & \\
\hline \multicolumn{5}{|c|}{ Malignant Lesions } \\
\hline 1 & Non-Hodgkin's Lymphomas & 7 & 17.07 & $20-70$ \\
\hline 2 & Hodgkin's Lymphoma & 1 & 2.43 & $<20$ \\
\hline 3 & Thymic carcinomas & 3 & 7.31 & $\begin{array}{l}20-30,60- \\
70(2)\end{array}$ \\
\hline 4 & Synovial Sarcoma & 1 & 2.43 & $20-30$ \\
\hline 4 & Malignant spindle cell lesion & 1 & 2.43 & 45 \\
\hline 5 & Malignant Fibrous histiocytic tumour & 1 & 2.43 & $40-70$ \\
\hline 6 & $\begin{array}{c}\text { Metastatic carcinoma deposits of } \\
\text { Unknown primary } \\
\end{array}$ & 3 & 7.31 & $48-65$ \\
\hline 8 & $\begin{array}{c}\text { NSCLS†, Adeno Ca, Anaplastic Ca - } \\
\text { deposits }\end{array}$ & 3 & 7.3 & \\
\hline \multirow[t]{2}{*}{7} & Suspicious of Malignancy & 2 & 4.87 & $50-65$ \\
\hline & Inconclusive & 3 & 7.31 & $25-50$ \\
\hline Total & & 25 & 60.97 & - \\
\hline
\end{tabular}

Table 1. Frequencies of Various Histological Diagnoses and Age Wise Distribution. $n=43$

*SFT- Solitary fibrous tumour, IST - Inflammatory pseudotumour, BSN Benign spindle cell neoplasm, †NSCLC - Non small cell lung carcinoma

\begin{tabular}{|l|c|c|c|c|}
\hline Compartment & Superior \% & Anterior \% & Middle \% & Posterior \% \\
\hline
\end{tabular}

\begin{tabular}{|c|c|c|c|c|}
\hline Number of cases & $21(48.8)$ & $14(32.5)$ & $3(7.3)$ & $5(11.6)$ \\
\hline Benign & $12(27.9)$ & $3(7.3)$ & $1(2.4)$ & $2(4.87)$ \\
\hline Malignant & $7(17.7)$ & $8(19.5)$ & $2(4.87)$ & $3(7.3)$ \\
\hline Inconclusive & $1(2.4)$ & $2(4.87)$ & - & - \\
\hline Suspicious & $1(2.4)$ & $1(2.4)$ & - & - \\
\hline \multicolumn{5}{|r|}{ Table 2. Compartmental Distribution of Various Lesions $\boldsymbol{n}=43$} \\
\hline
\end{tabular}

\begin{tabular}{|c|c|c|c|c|}
\hline Study from & $\begin{array}{c}\text { New Delhi } \\
\text { (\%) }\end{array}$ & $\begin{array}{c}\text { Rajasthan } \\
\text { (\%) }\end{array}$ & Nepal (\%) & Present (\%) \\
\hline $\begin{array}{c}\text { Total no of } \\
\text { cases }\end{array}$ & $116(100)$ & $139(100)$ & $27(100)$ & $43(100)$ \\
\hline Malignant & $32(27.6)$ & $93(66.9)$ & $7(25.9)$ & $21(48.8)$ \\
\hline Benign & $40(34.5)$ & $32(23.0)$ & $18(66.7)$ & $18(41.8)$ \\
\hline $\begin{array}{c}\text { Non- } \\
\text { neoplastic }\end{array}$ & $44(37.9)$ & $32(23.0)$ & - & - \\
\hline Inconclusive & 00 & $14(10.1)$ & $2(7.4)$ & $5(11.6)$ \\
\hline
\end{tabular}

Table 3. Comparison of Benign and Malignant Lesions in Different Indian Studies

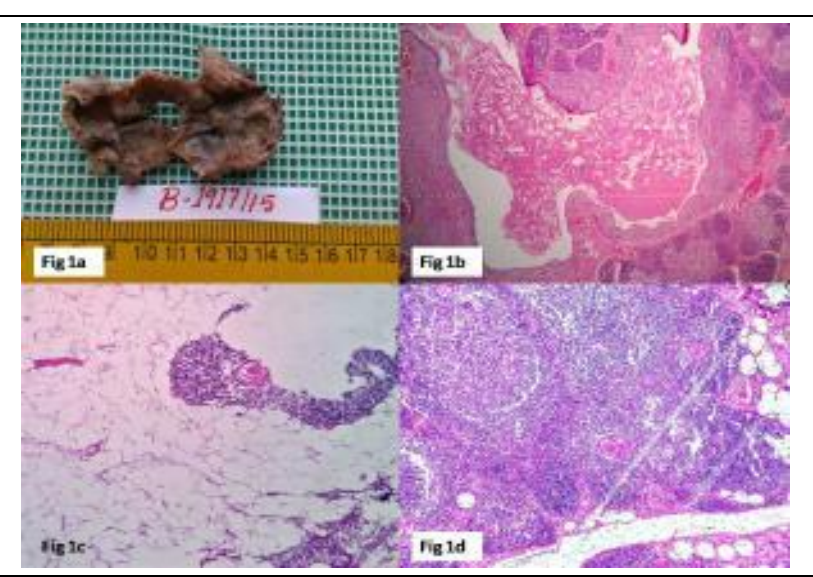

Figure 1. 1a. Gross photograph of unilocular thymic cyst in cut open state. 1b. Cyst -lined by thymic tissue, with luminal secretions and cholesterol clefts. 1c. Thymic lipoma-more than $80 \%$ of adipose tissue with islands of thymic tissue. 1d. Thymic hyperplasia-greater than $50 \%$ of thymic tissue- (H\&E 40X).

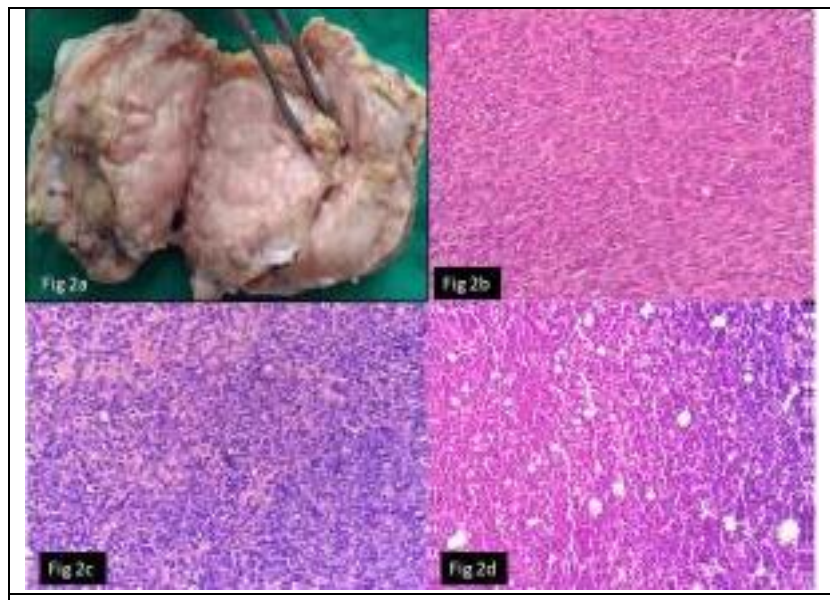

Figure 2. 2a. Gross photograph of thymoma- encapsulated nodular grey white tumour. $2 b$. Type A-Spindle/medullary thymoma with bland spindle and oval epithelial cells and no lymphocytes. 2c. Type AB-Mixed thymoma with mixture of lymphocyte poor type $A$ and lymphocyte rich $B$ thymoma like areas. 2 d. Type B1-lymphocyte rich/cortical thymoma with scattered epithelial cells in prominent population of lymphocytes (H\&E 40X).

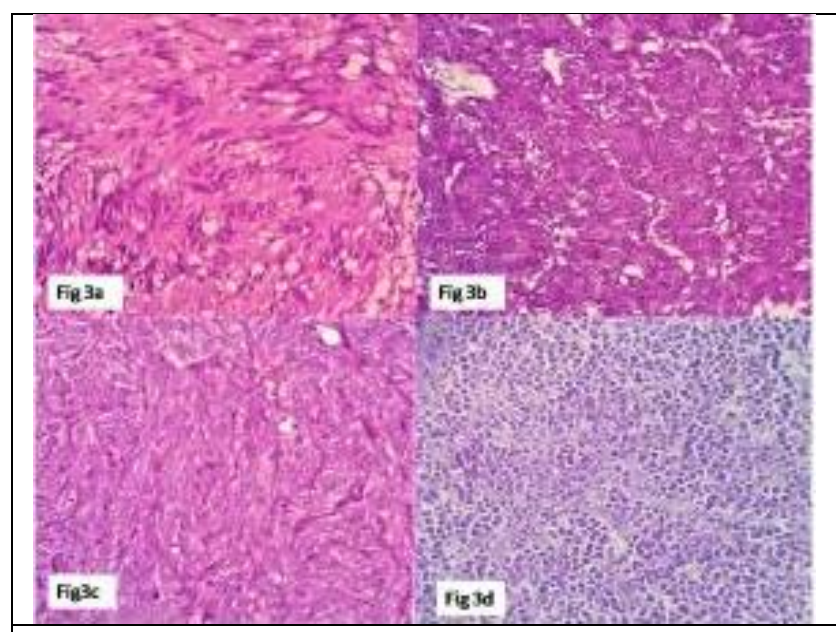

Figure 3. 3a. Ancient schwannoma-Spindle cells in both Antony A and $B$ patterns, microcystic areas and mild cellular

polymorphism. 3 b. Thymic adenocarcinoma-Pleomorphic epithelial cells as nests and glands. 3c. Monophasic synovial sarcoma- spindle shaped cells in fascicular pattern. $3 d$. Diffuse large B cell lymphoma- Effacement of architecture replaced by neoplastic lymphocytes 2-4 times larger than RBCs and large cleaved nucleoli showing prominent nucleoli- (H\&E 40X).

germ cell tumours, neurogenic tumours, and mesenchymal tumours of both benign and malignant nature. Mediastinal lesions are not freely accessible for routine biopsy techniques of fine needle aspiration (FNA) or Needle core biopsy (FNB). Imaging techniques like Ultrasound (US) and Computed tomography (CT) guided aspirations and needle core biopsies aid in getting adequate material in cases of the inaccessible and non resectable lesions. In cases of resectable lesions surgical excision can be done and submitted to histopathological examination. A definitive pathological diagnosis is essential for further treatment and management of patients especially in cases of malignancies where surgical resection is not feasible. Hence it is important for the pathologists to be familiar with the different mediastinal lesions that can present with wide variations. The present study is to put forth the histopathological spectrum of various mediastinal tumours that were encountered in the 
Department of Pathology, a tertiary care hospital in Andhra Pradesh, India.

\section{METHODS}

The present study is a retrospective study over a period of 3 $1 / 2$ years from June 2015 - December 2018. A total number constituted of about 43 mediastinal lesions and samples were obtained by either FNA or FNB wherever possible. In cases where the masses were not freely accessible nor resectable the samples were obtained either by Ultra sound guided/ CT guided needle aspirations or needle core biopsies. The biopsies, and surgically resected specimens where surgical resection was possible, were sent for histopathological examination to the Department of Pathology, GSL Medical College, Rajamahendravaram, a tertiary care centre in Andhra Pradesh, India.

All FNA smears were stained with routine Haematoxylin \& Eosin and Papanicolaou stains. Needle core Biopsies and surgically resected specimens were processed by routine formalin fixation, paraffin embedding, and sections were stained by Haematoxylin \& Eosin staining. IHC was done in cases of histopathological ambiguity. In a total number of 43 cases included in the study 17 (39.53\%) cases were FNAs, 5 (11.63\%) cases were Needle core biopsies and 21 (48.84\%) cases were surgically resected specimens. The data with respect to age, gender and final histopathological diagnosis was retrieved and reviewed from the histopathology records of department of pathology. Lesions arising from the pleura, lung, pericardium, rib cage were excluded from the study.

\section{RESULTS}

Present study is a retrospective study constituting of about a total of (43) cases of mediastinal lesions. Out of these 43 cases 17 (39.53\%) were CT guided FNACs, 5 (11.63\%) were CT guided FNBs and 21 (48.84\%) were excised specimens. Definitive diagnosis was not achieved in 2 cases of malignancies and no opinion was possible on samples of 3 cases as material was not adequate or necrosed. 27 cases $(62.8 \%)$ were male and $16(37.2 \%)$ were female patients, $\mathrm{M}$ : $\mathrm{F}$ ratio being 1.7. Age distribution of all these cases was between $04-70$ yrs. ${ }^{1-12}$ Out of total 43 cases we encountered 39 cases ( $90.60 \%$ ) were in adult age group ( $>16$ yrs.) and the mean age in adults was (47.7 yrs.). ${ }^{3-13}$ The remaining 4 (9.3\%) cases were in paediatric age group ( $<16$ yrs.) aged between 04-15 years (9.30\%) with mean age of 9 years, of these four paediatric cases two were benign lesions diagnosed as thymic cysts (Fig-1a \& b) aged 04 and 07 yrs. ${ }^{14,15}$ and the other two were cases of lymphomas one Hodgkin's and the other Non-Hodgkin's lymphoma aged 11 and 15 years indicating that the common malignant lesions in paediatric age group are lymphomas. In the adult age group 18(41.8\%) were benign lesions and 21 (48.84\%) were malignant lesions out of which three cases were of suspicious of malignancy where definitive diagnosis could not be established. This correlated with the present study and studies from Rajasthan by Dexit R, Shah N Set al ${ }^{1}$ and from Denmark by Larsen SS, Krasnik $M$ at al7 unlike the studies from Nepal by Karki S, Chalse $S$ et al ${ }^{12} \&$ New Delhi by Riti Aggarwal, Seema Rao et $\mathrm{al}^{3}$ who encountered more benign lesions than malignant lesions in their studies.

Thymic cysts are both congenital and acquired, congenital cysts are derived from remnants of the thymo-pharyngeal duct typically unilocular and contain clear fluid whereas acquired cysts are more common and multilocular arise in association thymomas, lymphomas and germ cell tumours, our case is unilocular in child aged 4 yrs. We encountered also a case of thymic lipoma and thymic hyperplasia each (Fig. 1c \& 1d). Thymic lipoma is a rare encapsulated tumour, asymptomatic without any sex predilection. In normal thymus the fat content constitutes about $50-80 \%$ and in thymic lipomas it accounts for as much as $95 \%$. Thymic hyperplasia is defined as diffuse symmetric enlargement of thymus which retains its normal shape and have more than $50 \%$ of thymic tissue. We encountered one case of thymic hyperplasia in anterior compartment who presented with difficulty in breathing.

One case of colloid goiter was encountered in superior compartment in adult patient in the present study. Mediastinal goiter generally represents direct contiguous growth of a goiter in to the anterior or superior compartment. 15

Thymomas were more common benign primary neoplastic lesions encountered in adult age group which are rare and were not seen in paediatric age group in the present study. 1,4 Thymic carcinomas in general account for $20 \%$ of thymic epithelial tumours with mean age of 50 yrs., in our study mean age was 52 yrs.

Primary mediastinal lymphomas usually occur in anterior mediastinum and account for $20 \%$ of neoplasms in adults and about $50 \%$ in paediatric age group $3,8,15$ which correlates with the present study.

\section{DISCUSSION}

In the present study of 43 cases of mediastinal lesions analysed malignant lesions were more frequent $21(48.84 \%)$ than benign lesions 18 (41.8\%), which is comparable to many other studies 1,7. Primary thymic neoplasms, and lymphomas are the most common tumours in mediastinum, nearly $50 \%$ of all mediastinal masses were anterior mediastinal tumours, which included thymic cysts, thymomas, a case of thymic lipoma, teratoma, thymic hyperplasia, colloid goiter thyroid each and lymphomas ${ }^{5}$. In the middle compartment lesions, we encountered were mostly lymph nodal metastatic deposits, whereas in the posterior mediastinum neurogenic tumours were more common. The most common benign lesion encountered in adults was thymoma $8(20.5 \%)$ of different types like A (1), AB (2), B1 (3) and B2 (2) (Fig. 2a-d) and most common malignant lesions were lymphomas 8 (20.5\%) including both Non-Hodgkin's lymphoma 7 (17.0\%)cases and one case of Hodgkin's Lymphoma followed by metastatic lesions and sarcomas(figure 3a-d) indicating thymomas and lymphomas occurred almost with similar frequencies in the present study. The other lesions included were one germ cell tumour Mature teratoma, benign mesenchymal lesions namely Schwannoma, Solitary fibrous tumour, benign spindle cell lesion, and Inflammatory pseudotumour one each. Extra gonadal teratomas per se are rare and mediastinal mature teratomas are still rarer entity. We encountered one case of mature teratoma in anterior mediastinum. The malignant mesenchymal lesions we encountered were synovial sarcoma, malignant fibrous histiocytoma etc. Out of two cases of inconclusive opinion one case of small round cell tumour posed difficulty in coming to a definitive opinion as to whether it is a case of Germ cell 
tumour or Non-Hodgkin's Lymphoma and the other one which was between poorly differentiated carcinoma and NonHodgkin's lymphoma. Immunohistochemical study could not be done as these were FNA samples. In other three cases two FNB and one FNA material obtained was either necrotic or inadequate and hence opinion could not be given.

Frequencies of various histological diagnoses of mediastinal lesions and age wise distribution in the present study were shown in Table 1.

The most common compartmental distribution of the mediastinal lesions involved in the present study were superior and anterior, benign tumours were more common in superior compartment whereas malignant tumours occurred more frequently in anterior compartment which differs with studies from New Delhi by Riti Aggarwal, Seema rao et al, 3 Japan by Takeda S, Miyoshi S et al, ${ }^{4}$ Bengalurur by H J Gayatri, Jayanth K Das et al, ${ }^{5}$ China by Tingting Liu, Lika A Fasih ${ }^{6}$ and, Nepal by Karki S, Chalse $S$ et al ${ }^{12}$ where the anterior compartment involvement was more common- Table 2 .

In the present study, the most common tumours encountered in the mediastinum benign being thymomas and malignant were lymphomas. Studies from New Delhi by Riti Aggarwal, Seema rao et al, ${ }^{3}$ Japan by Takeda S, Miyoshi S, Akashi A et $\mathrm{al}^{4}$, Bengaluru by $\mathrm{H}$ J Gayatri Jayanth $\mathrm{K}$ Das et al, ${ }^{5}$ China by Tingting Liu, Lika'a Fasih Y et al ${ }^{6}$ and Nepal by Karki $\mathrm{S}$, Chalse $\mathrm{S}$ et al 12 all show thymomas as most common benign mediastinal lesion followed by Lymphomas as most common malignant lesions which correlates with the present study in adults- Table 3.

The other benign tumours encountered in the present study were extra gonadal mature teratoma, schwannoma, benign mesenchymal (BST) lesions like fibrohistiocytic lesion, solitary fibrous tumour (SFT), inflammatory pseudo tumour (IST) and colloid goiter one each. Malignant tumours encountered other than thymic carcinomas and Lymphomas were Synovial Sarcoma, Malignant spindle cell lesion, Malignant Fibrous histiocytic tumour (MFH) one each, three cases of Metastatic carcinoma deposits of Unknown primary, and three cases of metastatic lymph node deposits in mediastinum of Non-small cell lung carcinoma (NSCLS), Adeno Carcinoma, Anaplastic Carcinoma.

In paediatric cases in the present study anterior compartment was seen to be involved frequently in which thymic cysts and lymphomas were encountered which is similar to the study by Juanpere $\mathrm{S}$, Canete $\mathrm{N}$ et al ${ }^{15}$. Thymic cysts were uni/multiloculated and was an incidental finding in one case while in the other case was detected while investigating for pyrexia and cough.

\section{CONCLUSIONS}

The present study indicates that malignant lesions are commoner in mediastinum especially lymphomas than other benign lesions. The same conclusion is seen in several other studies. Accurate and precise diagnosis is important in mediastinal lesions. It has to be determined as to whether the lesion is benign or malignant; and if malignant the grade and stage of the lesions should be determined for further management. Awareness of histopathological spectrum of lesions that can occur in the mediastinum is important to clinicians, radiologists as well as pathologists. Minimally invasive techniques like USG/CT guided FNA or FNB sampling of mediastinal lesions considerably help in arriving at a definitive final histopathological diagnosis. Immunohistochemistry can be done in addition to routine staining techniques for confirmation wherever necessary. The definitive diagnosis will guide the clinician to plan appropriate treatment as early as possible which differs according to the type of lesion to reduce the morbidity and mortality of the patients, especially in cases of malignancy.

\section{ACKNOWLEDGMENT}

We would like to thank Mr. Maheshwara Choudhary, Senior technician, Department of Pathology for the expert technical help.

\section{REFERENCES}

[1] Dixit R, Shah NS, Goyal M, et al. Diagnostic evaluation of mediastinal lesions: analysis of 144 cases. Lung India 2017;34(4):341-8.

[2] Dasgupta S, Bose D, Bhattacharyya NK, et al. A clinicopathological study of mediastinal masses operated in a tertiary care hospital in Eastern India in 3 years with special reference to thymoma. Indian J Pathol Microbiol 2016;59(1):20-4.

[3] Agarwal R, Rao S, Chopra P, et al. Morphological spectrum of mediastinal lesions with special emphasis on evaluation of needle biopsy: an experience from tertiary care hospital. Indian J Med Res 2016;144(4):544-51.

[4] Takeda S, Miyoshi S, Akashi A, et al. Clinical spectrum of primary mediastinal tumours: a comparison of adult and paediatric populations at a single Japanese institution. J Surg Oncol 2003;83(1):24-30.

[5] Gayathridevi HJ, Das JK, Pasha M, et al. Retrospective analysis of mediastinal lesions - a tertiary care center experience. SSRG-IJMS 2015;2:5-12.

[6] Liu T, Al-Kzayer LFY, Xie X, et al. Mediastinal lesions across the age spectrum: a clinicopathological comparison between paediatric and adult patients. Oncotarget 2017;8(35):59845-53.

[7] Larsen SS, Krasnik M, Vilmann P, et al. Endoscopic ultrasound guided biopsy of mediastinal lesions has a major impact on patient management. Thorax 2002;57(2):98-103.

[8] Duwe BV, Sterman DH, Musani Al. Tumours of mediastinum. Chest 2005;128(4):2893-909.

[9] Aroor AR, Prakasha SR, Sheshadri S, et al. A study of clinical characteristics of mediastinal mas. J Clin Diagn Res 2014;8(2):77-80.

[10] Macciarini $P$, Ostertag $H$. Uncommon primary mediastinal tumours. Lancet Oncol 2004;5(2):107-18.

[11] Temes R, Chavez T, Mapel D, et al. Primary mediastinal malignancies: finding in 219 patients. West J Med 1999;170(3):161-6.

[12] Karki S, Chalse S. Analysis of mediastinal lesions: a study of 27 cases. Journal of Pathology of Nepal 2011;1:114-7.

[13] Kumar N, Kumar R, Bera A, et al. Thymoma Clinical experience from a tertiary care institute from North India. J Cancer Res Ther 2013;9(2):235-9. 
[14] Temes R, Allen N, Chavez T, et al. Primary mediastinal malignancies: in children: report of 22 patients and comparison to 197 adults. The Oncologist 2000;5(3):179-84.
[15] Juanpere S, Canete N, Ortuno P, et al. A diagnostic approach to the mediastinal masses. Insights Imaging 2013;4(1):29-52. 